\title{
Detection and Determination of Released Ions in the Presence of Nanoparticles: Selectivity or Strategy?
}

\author{
Deamelys Hernández, ${ }^{[a]}$ Gemma Cepriá ${ }^{+[a]}$ Francisco Laborda, ${ }^{[a]}$ and Juan R. Castillo*[a]
}

\begin{abstract}
Metallic nanoparticles can release ionic species, but also both species can occur in the same samples. Therefore, there is a need of efficient and cost-effective methods to determine these ionic species in the presence of the corresponding nanoparticles. Electroanalytical techniques open the door to this selective detection of NPs and their ions. In this work, a methodology that allows the direct determination of ionic silver $\left(\mathrm{Ag}^{+}\right)$in the presence of silver nanoparticles based on anodic stripping voltammetry was implemented. Silver nanoparticles were determined, after acidic digestion of the sample, by difference with respect to the total content of silver. The method was validated in terms of specific identification of silver ions, linearity, working range, limit of detection, limit of quantification, recovery, repeatability and rugged-
\end{abstract}

Keywords: Electroanalysis $\cdot$ Ionic silver $\cdot$ Silvernanoparticles ness. All parameters are adequate for an analytical method following Eurachem recommendations. The validated method was used to determine the concentration of $\mathrm{Ag}^{+}$and total silver in two commercial products of colloidal silver. The results were compared with those obtained by atomic absorption spectrometry in combination with an ultrafiltration step for isolation of ionic silver. There were no significant differences in the results. The proposed methodology benefits from the intrinsic selectivity of the electroanalysis methods, allowing to eliminate the steps of pretreatments of the samples, which are necessary in other techniques. The novelty of the article lies in the direct determination of $\mathrm{Ag}$ (I) ions in the presence of AgNPs, without the use of previous separation steps.

\section{Introduction}

The metallic nanoparticles (NPs), which are part of products of daily use (detergents, food packaging and textiles) or biomedical objects, can evolve with their use over time, changing their surface and releasing ions [1]. Metallic ions, specifically silver ions, have a strong antibacterial effect on a range of gram-negative and grampositive bacteria, which alter their population in external matrixes, e.g. water, external fluids [2]. Therefore, it is necessary to develop detection and characterization schemes of the species that could be generated during the aging of the products. In general, the detection of ions in the presence of the nanoparticles that generate them is relatively complicated and usually present interference problems [3]. For instance, the procedures used for the determination of silver in environmental samples, e.g. atomic absorption spectroscopy [4], neutron activation analysis [5], and inductively coupled plasma-mass spectroscopy [6], are based on the measurement of the total amount of silver, regardless of the actual silver species present in the sample. Nevertheless, modern electroanalytical techniques open the door to the selective detection of NPs and their corresponding ions even when they are both together in the same solution and avoiding the use of separation techniques prior to their determination.

Stripping voltammetry is perhaps the best technique currently available for direct measurement of trace metal ions in environmental samples [7]. The general procedure involves pre-concentration of the analyte on the electrode surface followed by the stripping step, where the analyte "deposit" dissolves back in solution because of a potential ramp. The latter step generates the electrochemical signal from which the species may be identified and quantified. This step is essential in the silver determination because silver deposits are highly stables and in many cases two electrochemical signals are obtained, this fact hinders the exact quantification of the silver ions. Several methods have been described in which acid solutions of different electrolytes are used to improve the electro-dissolution $[8,9]$.

The detection of silver via anodic stripping voltammetry has attracted significant attention over the past decades, by means of working with different types of electrodes. Due to its low toxicity and relatively low cost, carbon has always been an attractive material for electrodes in electroanalysis. Silver has been detected with a wide range of carbon electrodes [10] but only a limited number of articles have been published on the use of glassy carbon electrodes, most of them chemically modified $[11,12]$. Numerous articles discuss the determination

\section{[a] D. Hernández, G. Cepriá, ${ }^{+}$F. Laborda, J. R. Castillo}

Group of Analytical Spectroscopy and Sensors (GEAS), Institute of Environmental Sciences (IUCA), University of Zaragoza, Pedro Cerbuna 12, 50009 Zaragoza, Spain

E-mail: jcastilo@unizar.es

$\left.{ }^{+}\right]$In memoriam 
of silver by electrochemical techniques [12-17]. However, none addresses the direct detection and quantification of ionic silver $\left(\mathrm{Ag}^{+}\right)$in presence of silver nanoparticles (AgNP) using glassy carbon electrodes and its application in real samples containing colloidal and ionic silver.

In the present article we propose and validate a square-wave anodic stripping voltammetry method for the direct determination of $\mathrm{Ag}^{+}$in presence of AgNP. This method was applied to real samples and the results compared to those obtained by conventional techniques. To the best of our knowledge, this research accounts for the first report using square-wave anodic stripping voltammetry as a novel method to determine $\mathrm{Ag}^{+}$in presence of the corresponding AgNP in commercial healthcare products.

\section{Experimental Section}

\subsection{Chemicals}

All chemicals in this work were purchased from SigmaAldrich. Silver standard solutions were prepared daily by dilutions of a $1000 \mathrm{mgL}^{-1}$ stock solution. The silver nanoparticles suspensions were prepared daily by dilution of a $20 \mathrm{mg} \mathrm{L}^{-1}$ suspension. All solutions were made using ultrapure water of resistivity $18.2 \mu \Omega$ (Millipore) at $25^{\circ} \mathrm{C}$.

The electrolyte solutions used were $0.1 \mathrm{M}$ sodium perchlorate monohydrated.

\subsection{Methods}

\subsubsection{Determination of Ag by Square-wave Anodic Stripping Voltammetry (SWASV)}

The total $\mathrm{Ag}$ and $\mathrm{Ag}^{+}$were determined by SWASV. These determinations were carried out after dilution with $\mathrm{NaClO}_{4}(0.1 \mathrm{M})$ to reach a concentration within the working range. For the determination of total $\mathrm{Ag}$, the method was the same but preceded by the digestion of the samples for $2 \mathrm{~h}$ with the same volume of concentrated $\mathrm{HNO}_{3}$. Voltammetric measurements were carried out using an AutoLab PGSTAT-12 potentiostat (Utrecht, The Netherlands). The potentiostat was operated using Autolab 2.1 software (Utrecht, The Netherlands). The auxiliary electrode was a platinum electrode, while the reference electrode was a $\mathrm{Ag} / \mathrm{AgCl}$ electrode (BASi, USA). A glassy carbon electrode (GC, diameter $3 \mathrm{~mm}$ ) also was purchased from BASi and used as a working electrode.

The electrolyte solutions used were $0.1 \mathrm{M}$ sodium perchlorate monohydrated, pH 5.25. Samples were degassed thoroughly with $\mathrm{N}_{2}$ before each measurement. The glassy carbon electrode was polished with alumina, rinsed profusely with deionized water, sonicated in water for three minutes and rinsed again with deionized water. All glassware was cleaned with $50 \%$ nitric acid and stored in $1 \%$ nitric acid solution when not being used.

\subsubsection{Determination of Ag Using Atomic Absorption Spectroscopy (AAS)}

The total $\mathrm{Ag}$ and $\mathrm{Ag}^{+}$were confirmed by AAS using a flame atomic absorption spectrometer Perkin Elmer, AAnalysts 200 (Massachusetts, USA) equipped with a silver hollow-cathode-lamp operating at $2 \mathrm{~mA}$ and at a wavelength of $328.1 \mathrm{~nm}$. For the determination of total $\mathrm{Ag}$, the method was the same as describe above. While $\mathrm{Ag}^{+}$determination by AAS was accomplished after an ultrafiltration step of the sample. Nanosep Pall centrifugal ultrafilter devices with cut-off membranes of $3 \mathrm{kDa}$ (equivalent to a $2 \mathrm{~nm}$ hydrodynamic diameter). were used for $\mathrm{Ag}^{+}$separation. Ultrafilter devices were washed by centrifugation with $500 \mu \mathrm{L}$ of ultrapure water prior to use. $500 \mu \mathrm{L}$ of sample were subjected to centrifugation for $10 \mathrm{~min}$ at $9000 \mathrm{rpm}$ and $20^{\circ} \mathrm{C}$ (Thermo Heraeus Multifuge $\mathrm{X} 1 \mathrm{R}$, equipped with a fixed angle rotor for Eppendorf tubes, Walthman, USA).

\subsubsection{UV-visible Spectrophotometry}

The presence of AgNP in the samples was monitored by recording the surface plasmon resonance (SPR) band using a UV-visible double beam spectrophotometer (Jasco V-730, Japan) operated between 500 to $300 \mathrm{~nm}$ at a resolution of $1 \mathrm{~nm}$. The standards containing nanoparticles of $40 \mathrm{~nm}$ were prepared at a concentration of $5 \mathrm{mgL}^{-1}$. The studied samples were diluted to a concentration of approximately $5 \mathrm{mg} \mathrm{L}^{-1}$ with ultrapure water. Standards and samples were analyzed using $3.5 \mathrm{~mL}$ quartz cuvettes with $10 \mathrm{~mm}$ of path length.

\subsection{Validation}

Validation was performed following EURACHEM guide [18] in terms of identification of the $\mathrm{Ag}^{+}$, linearity, working range, limit of detection and limit of quantification, recovery, repeatability and ruggedness. The number of the replicates used for each assay was between four and ten.

Identification: To evaluated the reliability of the method, solutions of $0.5 \mathrm{mgL}^{-1}$ of silver $(\mathrm{n}=4)$ in $0.1 \mathrm{M}$ $\mathrm{NaClO}_{4}$ were used to identify the optimum conditions for Ag electrochemical detection. Silver was deposited at $-0.5 \mathrm{~V}$ for $120 \mathrm{~s}$. After an equilibration time of $5 \mathrm{~s}$ a single scan was carried out from 0 to $0.45 \mathrm{~V}$ with a step potential of $0.004 \mathrm{~V}$ and a scan rate of $0.04 \mathrm{~V} \mathrm{~s}^{-1}$.

Repeatability: In order to evaluate the intra-assay precision, six replicates $(n=6)$ at two concentrations (LC: low control at $10 \mu \mathrm{g} \mathrm{L}^{-1}$ and $\mathrm{HC}$ : high control at $20 \mu \mathrm{g} \mathrm{L}^{-1}$ ) were measured. The replicates were prepared under the same conditions and subjected to the conditions of measurements only once to avoid interference due to the possible oxidation of AgNP during the measurement process.

Linearity and working range: To evaluate linearity, three calibration curves were plotted considering the peak 
area (coulombs) as a function of the concentration $\left(\mu \mathrm{g} \mathrm{L}^{-1}\right)$. Four calibration solutions were prepared $(2.5$; $5.0 ; 10.0 ; 20.0 \mu \mathrm{g} \mathrm{L}^{-1}$ ) from silver standard stock solution $(\mathrm{n}=4)$. The response was linear from 2.5 up to $20 \mu \mathrm{gL}^{-1}$, lower concentrations showed a positive deviation from the calibration line. Regression analysis was performed with Origing 8.0.

Limits of detection (LOD) and quantification (LOQ): To establish the limits of detection and quantification the standard deviation of the intercept $\left(s_{a}\right)$ and the slope (b) of the three calibration curves were utilized. As the method prove to be linear, the LOD (1) and LOQ (2) were expressed as: $\mathrm{LOD}=3 \mathrm{~s}_{\mathrm{a}} / \mathrm{b}(1)$ and $\mathrm{LOQ}=10 \mathrm{~s}_{\mathrm{a}} / \mathrm{b}(2)$.

Recovery and ruggedness: Recovery was determined by comparing the responses results obtained by AAS and ASWSV for a sample of known concentration $\left(25 \mathrm{mg} \mathrm{L}^{-1}\right)$. The samples $(n=4)$ were quantified by AAS and then diluted adequately with $\mathrm{NaClO}_{4} 0.1 \mathrm{M}$ and quantified by ASWSV. Ruggedness was evaluated to establish if the method produces similar results when minor variations are introduced. In this case, the recovery was assessed changing the working electrode (GCE_1 and GCE_2) to analyze a solution containing $25 \mathrm{mgL}^{-1}$ of silver. The results were statistically compared using t-test.

\subsection{Samples}

Two commercial colloidal silver products, namely Biovedik (distributed by Alex Healthy and Natural Pvt Ltd Puducherry, India) and Wellness Colloidal Silver TM (manufactured by Source Naturals, Inc. Santa Cruz, USA) were analyzed. These products are recommended as health products intended for internal consumption or as surface sanitizers for external use. The products were kept in a dark place at room temperature until analysis. Some milliliters were taken and prepared as described in 2.2.1; 2.2.2 and 2.2.3 sections.

\section{Results}

In this work, we aim to develop a reliable, fast and accurate method to determine $\mathrm{Ag}$ ions in presence of AgNP. The determination was based on electroanalytical measurements, which is a desirable alternative due to the selective detection of NPs and their corresponding ions even when they are both together in the same solution. The method allowed to determine $\mathrm{Ag}^{+}$and total silver in samples containing colloidal silver. The presence of AgNPs was confirmed by the detection of the SPR bands in the spectrophotometric analysis. The estimation of the concentration of the nanoparticles in the samples was achieved by determining the difference between the total silver and the ionic silver concentrations.

\subsection{Validation}

Identification: Figure 1 shows typical anodic voltammograms for $\mathrm{Ag}(\mathrm{I})$ in the presence of $\mathrm{AgNPs}$ and the

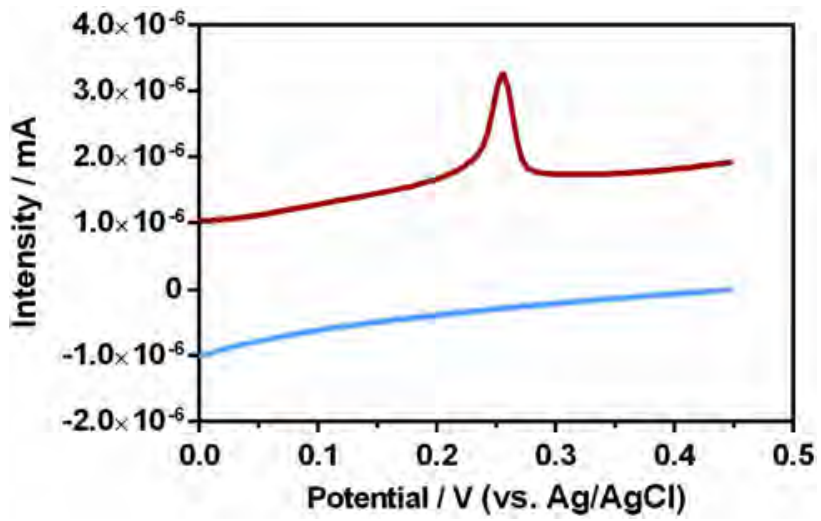

Fig. 1. SWASV of $0.05 \mathrm{mg} \mathrm{L}^{-1} \mathrm{Ag}(\mathrm{I})$ in presence of $60 \mathrm{~nm}$ AgNPs $\left(0.5 \mathrm{mgL}^{-1}\right)$ and $\mathrm{NaClO}_{4} 0.1 \mathrm{M}$ as supporting electrolyte (red). Supporting electrolyte voltammogram $\mathrm{NaClO}_{4} 0.1 \mathrm{M}$ as negative control (blue). $\mathrm{Ag}(\mathrm{I})$ was deposited at $-0.5 \mathrm{~V}$ for $120 \mathrm{~s}$. After an equilibration time of $5 \mathrm{~s}$ a single scan was carried out from 0 to $0.45 \mathrm{~V}$ with a step potential of $0.004 \mathrm{~V}$ and a scan rate of $0.04 \mathrm{~V} \mathrm{~s}^{-1}$.

supporting electrolyte $\left(\mathrm{NaClO}_{4} 0.1 \mathrm{M}\right)$. Using the instrumental parameters listed in 2.3 it was possible to obtain a single peak at $0.240 \pm 0.008 \mathrm{~V}$. The differences between the baseline of each measurement is due to the differences between the compositions of both samples. Other articles showed differences in baseline levels in the blank and standard [9]. Conditions in which two signals were obtained were discarded. The multiple signals may be related to having silver deposits with different crystalline structures [7].

Repeatability: The relative standard deviations (RSD) were $13.64 \%$ for HC and $8.54 \%$ for LC (Table 1 ).

Linearity and working range: The regression equation for the results and its correlation coefficient are showed in the Table 1, which describe a suitable correlation for an analytical method. The method was linear in the studied range, see also Figure 2.

Limit of detection (LOD) and quantification (LOQ): The values obtained for LOD and LOQ with the used

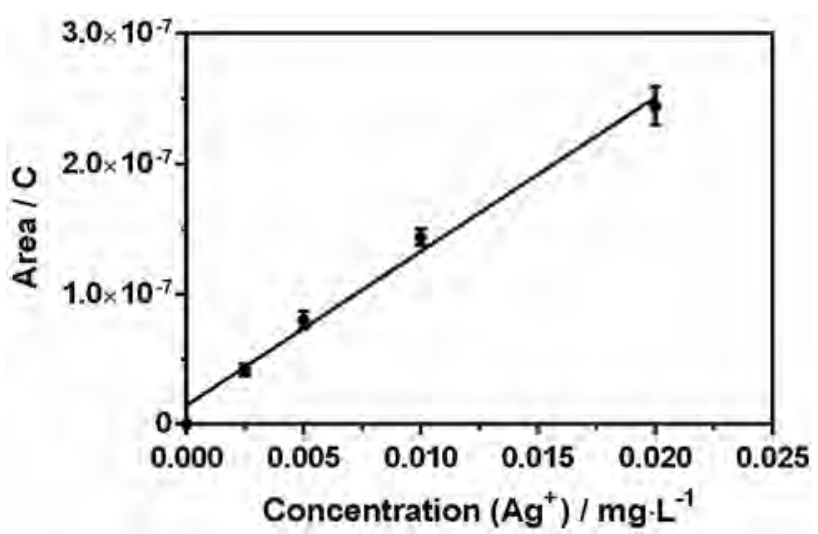

Fig. 2. SWASV calibration for $\mathrm{Ag}^{+}$in $\mathrm{NaClO}_{4} 0.1 \mathrm{M}$ 
Table 1. Repeatability, linearity, working range, recovery, ruggedness, limit of detection and quantification of the anodic square-wave stripping voltammetry method.

\begin{tabular}{lll}
\hline Parameter & Description & Value \\
\hline Repeatability & $20 \mu \mathrm{gL}^{-1}(\mathrm{n}=6)$ & $13.6 \%$ \\
& $10 \mu \mathrm{gL}^{-1}(\mathrm{n}=6)$ & $8.5 \%$ \\
Linearity & $\mathrm{R}^{2}=0.9985$ & $\mathrm{y}=1.310^{-5} \mathrm{x}+6.910^{-9}$ \\
Working range & $\mathrm{LOD}=3 \mathrm{~s}_{\mathrm{a}} / \mathrm{b}$ & $2.5-20 \mu \mathrm{g} \mathrm{L}^{-1}$ \\
Limit of detection & $\mathrm{LOQ}=10 \mathrm{~s}_{\mathrm{a}} / \mathrm{b}$ & $1.3 \mu \mathrm{g} \mathrm{L}^{-1}$ \\
Limit of quantification & $t$ test with two differente GC working electrodes & $4.2 \mu \mathrm{gL}^{-1}$ \\
Ruggedness & $25 \mathrm{mgL}^{-1}$ & no significant differences $(95 \%$ confidende level) \\
Recovery & & $92 \pm 1 \%$ \\
\hline
\end{tabular}

Table 2. Concentration of $\mathrm{Ag}$ total and released $\mathrm{Ag}^{+}$in commercial samples containing colloidal silver (Biovedik and Wellness).

\begin{tabular}{|c|c|c|c|c|c|}
\hline \multirow[t]{2}{*}{ Product } & \multicolumn{2}{|c|}{ Total Ag $\left(\mathrm{mgL}^{-1}\right)$} & \multicolumn{2}{|c|}{$\mathrm{Ag}^{+}\left(\mathrm{mg} \mathrm{L}^{-1}\right)$} & \multirow{2}{*}{$\begin{array}{l}\operatorname{AgNP}\left(\mathrm{mg} \mathrm{L}^{-1}\right) \\
\text { Diff. }\end{array}$} \\
\hline & $A A S$ & $A S W S V$ & $A A S$ & $A S W S V$ & \\
\hline $\begin{array}{l}\text { Biovedik } \\
\text { nominal Ag content } \\
>25 \mathrm{mg} \mathrm{L}^{-1}\end{array}$ & $20.9 \pm 0.4$ & $20.5 \pm 2.0$ & $15.0 \pm 1.0$ & $14.7 \pm 0.9$ & $5.9 \pm 0.1$ \\
\hline $\begin{array}{l}\text { Wellness } \\
\text { nominal Ag content } \\
30 \mathrm{mg} \mathrm{L}^{-1}\end{array}$ & $32.6 \pm 1.1$ & $32.0 \pm 2.0$ & $0.36 \pm 0.01$ & $0.4 \pm 0.1$ & $32.1 \pm 0.2$ \\
\hline
\end{tabular}

method were $1.3 \mu \mathrm{gL}^{-1}$ and $4.2 \mu \mathrm{gL}^{-1}$ respectively. This limits are highly comparable with those found in the literature.

Recovery and ruggedness: Recovery was above $90 \%$, which is appropriate for an analytical method. The method was robust, the statistical analysis did not report significant differences at a confidence level of $95 \%$ (Table 1).

\subsection{Analysis of commercial samples}

The commercial products tested were advertised to contain some form of silver (colloidal, hydro-sol or ionic) and the concentrations reported by the manufacturer are listed in Table 2. The validated method was used to determine the concentration of $\mathrm{Ag}^{+}$and total silver in the products by external calibration. Figure 3 shows the ASWSV voltam-

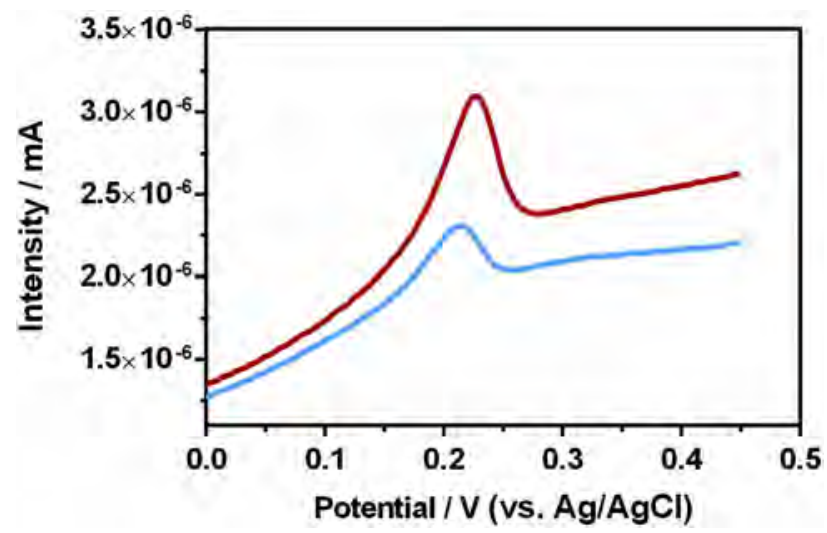

Fig. 3. SWASV of Wellness samples (red) and Biovedik sample (black) in $\mathrm{NaClO}_{4} 0.1 \mathrm{M}$. mograms obtained from both products. The results were compared with those obtained by atomic absorption spectrometry. No significant differences were observed when a t-test (95\% a confidence level) was applied.

The measured concentrations were fairly close to the nominal contents (Table 2). The content of ionic silver in the Biovedik sample constituted around the $70 \%$ of the total silver, while the AgNP concentration was $5.9 \pm$ $0.1 \mathrm{mg} \mathrm{L}^{-1}$. The Wellness sample contained only about $1 \%$ of ionic silver as long as the AgNP concentration was $32.1 \pm 0.2 \mathrm{mgL}^{-1}$. The method was effective for the determination of ionic silver in both samples, regardless ionic silver was a major or trace component.

Spectrophotometric analysis confirmed the presence of AgNP in the samples. The spectrum of both samples showed the typical SPR band of AgNP. Figure 4 shows the spectrums of Biovedik and Wellness samples together with the spectrum of AgNP standard solution (40 nm) at a concentration of $5 \mathrm{mg} \mathrm{L}^{-1}$. The samples Biovedik and Wellness exhibited strong absorption at 422 and $412 \mathrm{~nm}$, respectively, which confirms the presence of AgNP. The difference between the intensities of the spectra indicates that the concentration of nanoparticles in the Wellness sample is higher than in the Biovedik sample. This fact is in agreement with the result of the quantification by our electroanalytical method. The estimated concentration of AgNP in the samples was calculate by difference between total $\mathrm{Ag}$ and $\mathrm{Ag}^{+}$. Table 2 shows the mean concentration of AgNP in the commercial samples, calculated by averaging the result of the quantification by AAS and ASWSV methods. 


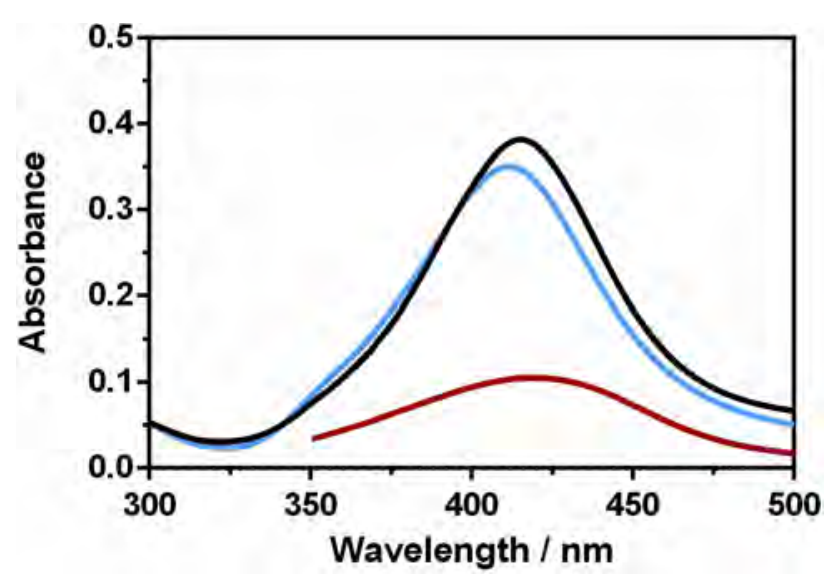

Fig. 4. Ultraviolet-visible absorption spectrum of a standard AgNP solution of $40 \mathrm{~nm}\left(5 \mathrm{mg} \mathrm{L}^{-1}\right)$ (black), Wellness (red) and Biovedik sample (blue).

\section{Discussion}

In this work, we addressed the voltammetric determination of $\mathrm{Ag}^{+}$in real samples. The obtained results demonstrate that we could efficiently and in a reproducible manner determine $\mathrm{Ag}^{+}$in presence of $\mathrm{AgNP}$. To the best of our knowledge there are no reports on using this methodology, which makes it a valuable alternative for the reliable determination of ions in the presence of its metallic nanoparticles. However, due to the lack of literature addressing this problem, it is difficult to establish a proper comparison. The results of the validation were in agreement with what has been published for methods determining silver in other systems (other working electrodes or modified electrodes) [19,20-22]. In this work, $\mathrm{Ag}^{+}$was properly identified and the achievement of a single signal was possible. Some authors refer the presence of multiple peaks in the voltammogram as a consequence of the deposition of silver with different crystalline structures [7]. In our opinion we obtained a single peak signal because of the extensive cleaning step of the glassy carbon electrode $\left(50 \% \mathrm{HNO}_{3}\right)$ before each measurement, making sure that the surface of the electrode was homogeneously clean for the new deposition. The non-modification of the surface of the electrode is an advantage of the proposed method, reducing the preparatory steps in comparison with other methods and hence the analysis time and the sources of uncertainty, as well as the number of reagents needed.

The repeatability was $13.6 \%$ for $\mathrm{HC}$ and $8.5 \%$ for $\mathrm{LC}$, which are in accordance with values adopted in the validation guides of bioanalytical methods, which allows a variation of up to $25 \%$ in the lower control and up to $15 \%$ in the upper control [23]. Values obtained were also in agreement with other electroanalytical methods which present about $10 \%$ variability $[7,9]$.

The linearity of methods for $\mathrm{Ag}^{+}$detection have been reported within working ranges similar to ours $[9,19]$.
The common procedures for the calculation of LOD and LOQ as three and ten times the standard deviation of a blank are not well-suited for electroanalytical techniques that exhibit a low background noise, in this case it is preferable to use the standard deviation of the intercept of the calibration curve [24]. The LOD and LOQ achieved in our case, are highly comparable with values already reported, in the literature it has been found higher $[8,4]$ and similar limits $[7,9,13,17,20]$. This allows the application of the method to samples with low concentration of ionic Ag.

Recoveries between 70 to $130 \%$ have been reported previously in the literature $[10,11]$. Our results are within this range, being $92 \%$ a recovery value suitable for analytical methods. Ruggedness is defined as measure of method capacity to remain unaffected by small, but deliberate variations in method parameters, providing an indication of the method reliability during normal usage [18]. Although we could not find comparable values in the literature for the evaluation of this parameter, the present method can be considered robust because there were no significant differences in the recovery of $\mathrm{Ag}^{+}$when measurements were done with two different glassy carbon electrodes.

The determination and quantification of silver ions in commercial products were achieved successfully. The measured concentrations were fairly close to the nominal Ag contents (Table 2). The content of ionic silver in Biovedik sample constituted around the $70 \%$ of the ionic silver and the AgNP concentration was $5.9 \pm 0.1 \mathrm{mgL}^{-1}$, while the Wellness sample contained only about one percent of ionic silver and the AgNP concentration was $32.1 \pm 0.2 \mathrm{mgL}^{-1}$. The method was effective for the determination of ionic silver both when it was the main component or when present at trace level. The results obtained for $\mathrm{Ag}^{+}$by AAS were in close accordance with the results obtained by ASWSV. To our knowledge this is the first report which accounts for application of $\mathrm{Ag}^{+}$ determination method in samples that contain silver nanoparticles.

\section{Conclusions}

Square-wave stripping voltammetry at a glassy carbon electrode is a useful method to measure $\mathrm{Ag}^{+}$selectively in presence of AgNP. The method showed to be selective, repeatable, robust and linear. The LOD and LOQ were $1.3 \mu \mathrm{gL}^{-1}$ and $4.2 \mu \mathrm{gL}^{-1}$, respectively. The method was successfully applied to two commercially available samples which contain ionic silver and silver nanoparticles. The Biovedik sample had $20.5 \pm 2.0 \mathrm{mgL}^{-1}$ of total silver of them $14.7 \pm 0.9 \mathrm{mg} \mathrm{L}^{-1}$ were $\mathrm{Ag}^{+}$. In this sample most of the silver was found as $\mathrm{Ag}^{+}$, and only $5.9 \pm 0.1 \mathrm{mg} \mathrm{L}^{-1}$ were as AgNP. On the other hand, the Wellness sample was constituted by $0.4 \pm 0.1 \mathrm{mgL}^{-1}$ of $\mathrm{Ag}^{+}$and $32.1 \pm$ $0.2 \mathrm{mgL}^{-1}$ of AgNP for a total content of silver of $32.0 \pm$ $2.0 \mathrm{mgL}^{-1}$. In both samples was possible to quantify 
adequately the $\mathrm{Ag}^{+}$in presence of $\mathrm{AgNP}$ this result was verified by comparison with an alternative AAS method.

\section{Acknowledgements}

This work was supported by the Spanish Ministry of Economy and Competitiveness and the European Regional Development Fund, project CTQ2015-68094-C2-1-R (MINECO/FEDER). D. Hernández acknowledges a Bank of Santander - University of Zaragoza grant.

\section{References}

[1] K. Tschulik, R. G. Palgrave, C. Batchelor-McAuley, R. G. Compton, Nanotechnology 2013, 24, 295502.

[2] C. Marambio-Jones, M. V. Hoek, J. Nanopart. Res. 2010, 12, $1531-1551$

[3] Z. Xiaoxia, L. Jingfu, Y. Chungang, C. Yongsheng, J. Anal. At. Spectrom. 2016, 31, 2285-2292.

[4] M. A. Karimi, S. Z. Mohammadi, A. Mohadesi, A. HatefiMehrjardi, M. Mazloum-Ardakani, L. S. Korani, A. A. Kabir, Sci. Iran. 2011, 18, 790-796.

[5] A. Nadkarni, G. H. Morrison, Anal. Chem. 1975, 47, 22852286.

[6] F. Laborda, E. Bolea, G. Cepria, M. T. Gomez, M. S. Jimenez, J. Perez-Arantegui, J. R. Castillo, Anal. Chim. Acta 2016, 904,10-32.

[7] D. E. Schildkraut, P. T. Dao, J. P. Twist, A. T. Davis, K. A. Robillard, Environ. Toxicol. Chem. 1998, 17, 642-649.

[8] Q. Y. Liu, B. D. Liu, F. Yuan, H. Zhuang, C. Wang, D. Shi, Y. K. Xu, X. Jiang, Appl. Surf. Sci. 2015, 356, 1058-1063.

[9] T. J. Davies, Analyst. 2016, 141, 4742-4748.

[10] S. Kleijn, Angew. Chem. Int. Ed. 2014, 53, 3558-3586
[11] M. C. Radulescu, A. C. M. Radulescu, B. Bucur, M. P. Bucur, G. L. Radu, Sensors 2010, 10, 11341-11351.

[12] I. Saok, K. Tyszczuk-Rotko, J. Electroanal. Chem. 2018, 808, 204-210

[13] V. Y. Maldonado, P. J. Espinoza-Montero, C. A. Rusinek, G. M. Swain, Anal. Chem. 2018, 90, 6477-6485

[14] J. Wang, T. Martinez, Anal. Chim. Acta 1988, 207, 95-102.

[15] E. Lorenzo, H. D. Abruña, J. Electroanal. Chem. 1992, 328, 111-125.

[16] S.-S. Hunag, Z.-G. Chen, B.-F. Li, H.-G. Lin, R.-Q. Yu, Analyst 1994, 119, 1859-1862.

[17] Z. Koudelkova, T. Syrovy, P. Ambrozova, Z. Movarec, L. Kubac, D Hynek, L Richtera, V. Adam, Sensors 2017, 17,1832-1846

[18] The Fitness for Purpose of Analytical Methods - A Laboratory Guide to Method Validation and Related Topics, 2nd ed. (Eds.: B. Magnusson and U. Örnemark). 2014

[19] M. Javanbakht, F. Divsar, A. Badiei, F. Fatollahi, Y. Khaniani, M. R. Ganjali, P. Norouzi, M. Chaloosi, G. M. Ziarani, Electrochim. Acta 2009, 54, 5381-5386

[20] A. Shah, S. Ud-Din Khan, U. A. Rana, J. Chem. Soc. Pak. 2015, 37, 919-929

[21] H. El-Mai, E. Espada-Bellido, M. Stitou, M. García-Vargas, M. D. Galindo-Riaño, Talanta 2016, 151, 14-22

[22] I. Sadok, K. Tyszczuk-Rotko, J. Electroanal. Chem. 2018, 808, 204-210

[23] Bioanalytical Method Validation Guidance for Industry. FDA. Reviewed in May 2018.

[24] A. Shrivastava, V. B. Gupta, Chron. Young Sci. 2011, 2, $21-$ 25.

Received: August 24, 2018

Accepted: November 14, 2018

Published online on 


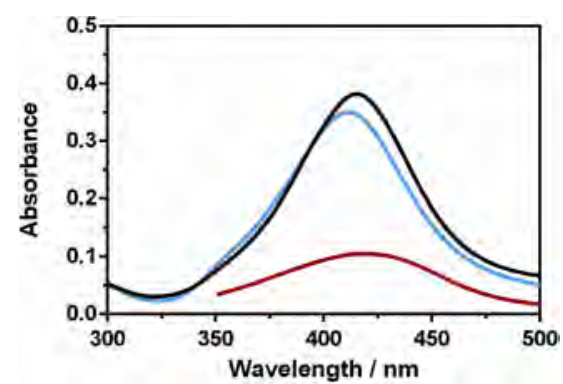

D. Hernández, G. Cepriá, F.

Laborda, J. R. Castillo*

$1-7$

Detection and Determination of

Released Ions in the Presence of

Nanoparticles: Selectivity or

Strategy? 